\title{
Fluorescent proteins in dominant mesophotic reef-building corals
}

\author{
Melissa S. Roth ${ }^{1, *}$, Jacqueline L. Padilla-Gamiño ${ }^{2}$, Xavier Pochon ${ }^{3,4}$, \\ Robert R. Bidigare ${ }^{5}$, Ruth D. Gates ${ }^{5}$, Celia M. Smith ${ }^{6}$, Heather L. Spalding ${ }^{6}$
}

${ }^{1}$ Department of Plant and Microbial Biology, University of California Berkeley, 441 Koshland Hall, Berkeley, California 94720-3201, USA

${ }^{2}$ Department of Biology, California State University Dominguez Hills, 1000 E. Victoria Street, Carson, California 90747, USA

${ }^{3}$ Environmental Technologies, Coastal \& Freshwater Group, Cawthron Institute, 98 Halifax Street East, Nelson 7010, New Zealand

${ }^{4}$ Institute of Marine Science, University of Auckland, Private Bag 92019, Auckland 1142, New Zealand

${ }^{5}$ Hawai'i Institute of Marine Biology, PO Box 1346, Kāne'ohe, Hawai'i 96744, USA

${ }^{6}$ Department of Botany, University of Hawai'i at Mānoa, 3190 Maile Way, Honolulu, Hawai’i 96822, USA

\begin{abstract}
Reef-building corals inhabiting the mesophotic zone (30-150 m) not only survive but thrive in light-limiting environments. Similar to shallow corals, mesophotic corals also exhibit coral fluorescence. Because fluorescent proteins (FPs) absorb high-energy light and emit lowerenergy light, FPs could play an important role in mesophotic coral physiology and ecology. For 4 species of the Hawaiian mesophotic reef-building coral Leptoseris (65-125 m), we investigated the abundance of fluorescent morphs, types of FPs, fluorescence emission phenotypes, and the physiological relationship between coral fluorescence and endosymbiotic Symbiodinium (dinoflagellate; Dinophyta). Cyan/green coral fluorescence emission was widespread in mesophotic Leptoseris spp.; more than $70 \%$ of corals fluoresced, yet fluorescent and nonfluorescent corals cooccurred at all depths investigated. Coral fluorescence was attributed to 2 proteins, a cyan fluorescent protein (CFP, $\lambda_{\text {ex }}=424 \mathrm{~nm}, \lambda_{\text {em }}=490 \mathrm{~nm}$ ) and a green fluorescent protein $\left(\mathrm{GFP}, \lambda_{\text {ex }}=478 \mathrm{~nm}\right.$, $\lambda_{\mathrm{em}}=502 \mathrm{~nm}$ ). The type of FP in Leptoseris colonies was correlated with depth; CFP was dominant in corals from shallower depths (65-85 m), GFP was dominant in corals from deeper depths (96-125 m), and CFP and GFP were present in corals from middle depths (86-95 m). Coral FP emission was primarily localized in the coenosarc and/or the oral disc. Symbiodinium from corals with and without fluorescence emission had similar genotypes, abundances, photosynthetic pigments, photosynthetic efficiencies, photosynthetic rates, and chlorophyll excitation spectra. As such, it is unlikely that these FPs play a significant role in enhancing symbiont photosynthesis. The high abundance of fluorescent morphs $(>70 \%)$ dominating this energetically limited environment may suggest that FPs play an integral and conserved physiological role in corals.
\end{abstract}

KEY WORDS: Photobiology - Ecophysiology - Fluorescent proteins - Green fluorescent proteins · GFP $\cdot$ Coral ecology $\cdot$ Leptoseris spp. D Deep water $\cdot$ Mesophotic coral ecosystems $\cdot$ MCE

\section{INTRODUCTION}

Mesophotic coral ecosystems (MCEs), which inhabit deep fore-reef zones, are similar to shallow reefs in that hermatypic corals build a complex structure that becomes the foundation of the community.

\footnotetext{
${ }^{*}$ Corresponding author: melissa.s.roth@gmail.com
}

In contrast to shallow reefs, the physical environment of the mesophotic zone is characterized by low solar irradiance with blue spectral enrichment, low wave disturbance, reduced temperatures, and often a higher abundance of upwelled nutrients (Lesser et al. 2009, Kahng et al. 2010). Furthermore, mesophotic

(C) The authors 2015. Open Access under Creative Commons by Attribution Licence. Use, distribution and reproduction are unrestricted. Authors and original publication must be credited. 
reefs are less vulnerable to stressors such as overfishing, climate change, and pollution than shallow reefs (Bak et al. 2005, Lesser et al. 2009). Because shallow and deep reefs are linked physically and biologically, there is the potential for mesophotic ecosystems to serve as refugia and a source/sink for shallow species (Lesser et al. 2009, Kahng et al. 2010). The difficulties accessing this zone limit knowledge of the productivity, physiology, and ecology of mesophotic communities (Bak et al. 2005, Lesser et al. 2009, Kahng et al. 2010). While mesophotic coral reefs are found from $30 \mathrm{~m}$ to over $150 \mathrm{~m}$ depths, this study focuses on dominant reef-building corals at depths below $60 \mathrm{~m}$. Many mesophotic corals such as Leptoseris spp. are restricted to these extreme low-irradiance environments (Rooney et al. 2010). Understanding what drives the distribution, biological interactions, or physiological traits of mesophotic corals may provide unique insights to clarify the paradox of reef-building corals flourishing under extreme low-irradiance conditions.

Reef-building scleractinian corals host endosymbiotic dinoflagellates from the genus Symbiodinium. In shallow corals, much of the energy needed for calcification of coral reefs is provided by photosynthetic products produced by Symbiodinium (Muscatine 1990). While obligate symbiotic corals have been observed as deep as $165 \mathrm{~m}$ (Maragos \& Jokiel 1986), the extent to which mesophotic corals rely on photosynthetic products from Symbiodinium remains poorly understood. The downwelling irradiance in the mesophotic zone $(\sim 65-115 \mathrm{~m})$ is about $3-10 \%$ of surface irradiance (Kahng et al. 2012). The dramatic decline in the quantity of photosynthetically active radiation (PAR) is compounded by a remarkable change in quality (spectral composition) at depth. Blue wavelengths penetrate most deeply in clear oceanic waters and are the most abundant wavelength at depth, while red wavelengths and ultraviolet radiation are significantly reduced at depth (Kirk 1994). The deep mesophotic zone in the present study $(65-125 \mathrm{~m})$ is an extreme low-irradiance habitat akin to deeply shaded terrestrial systems, but with blue rather than red spectral enrichment to the benefit of deep water algae with chlorophyll $a(\mathrm{chl} a)$ based light harvesting systems. The irradiance spectral composition and intensity are key regulating components of corals and Symbiodinium on multiple temporal and spatial scales (Roth 2014). In mesophotic photosynthetic communities, irradiance is a determining factor that is likely to have profound effects on coral and symbiont physiology and ecology.
Mesophotic reef-building corals may use a variety of strategies to live in an extreme low-irradiance environment, including reduced energetic requirements, increased rates of heterotrophy, and flattened skeletal morphology to optimize light collection (Kühlmann 1983, Lesser et al. 2009, Kahng et al. 2010). While Symbiodinium in shallow-water corals can vary concentrations of photosynthetic pigments, thereby affecting light-harvesting capabilities, photosynthetic efficiency, and rates of photosynthesis with depth (see Falkowski et al. 1990), Symbiodinium spp. in mesophotic-restricted corals surprisingly appear to lack these conspicuous physiological acclimatizations (see Kahng et al. 2014). Investigations into mesophotic-restricted corals and their symbionts, which are successful in these extreme lowirradiance environments, may provide novel insights into coral and symbiont biology.

Coral photobiology, fluorescent proteins (FPs), and mesophotic habitats pose intriguing research opportunities. FPs have the potential to play important roles in the physiology of corals and their symbionts because they absorb higher-energy irradiance (primarily blue wavelengths) and emit lowerenergy irradiance. Coral fluorescence emission is ubiquitous in shallow corals; $97 \%$ of reef flat corals at a site on the Great Barrier Reef exhibit medium to high levels of fluorescence (Salih et al. 2000). While coral fluorescence has been observed from mesophotic-restricted corals (Schlichter \& Fricke 1990, Kahng et al. 2012), the distribution and abundance of fluorescent coral morphs in the deep mesophotic zone is unknown. Additionally, shallow corals exhibit different patterns of fluorescence emission including uniform (fluorescence over the whole coral), highlighted (varying fluorescence with concentrations in particular anatomical regions such as the oral disc), and complementary (different FPs expressed in specific anatomical regions) (Gruber et al. 2008). Cnidarians produce a rainbow of FPs, including cyan fluorescent proteins (CFPs), green fluorescent proteins (GFPs), yellow fluorescent proteins (YFPs), red fluorescent proteins (RFPs), and purple-blue fluorescent proteins that do not fluoresce (also known as pocilloporins or chromoproteins) (Alieva et al. 2008). Regardless of the color of emission or lack of emission, FPs all have a similar protein sequence and structure (Alieva et al. 2008). The dominant fluorescence in shallow corals is cyan/green emission (Vermeij et al. 2002, Gruber et al. 2008). In Leptoseris corals, cyan/green coral fluorescence has been observed from both the shallow Caribbean coral L. cucullata (Mazel et al. 
2003) and the mesophotic-restricted corals L. fragilis (Red Sea; Schlichter \& Fricke 1990) and Leptoseris spp. (Hawai'i; Kahng et al. 2012). However, the fluorescent pigment of $L$. fragilis has not been identified and it is unlikely to be a FP (Matz et al. 2006a). Additionally, mesophotic corals that have been studied for coral FPs include Favia sp. from the Red Sea in which green and red fluorescence was observed and 11 potential FP homologs were identified (Pooyaei Mehr et al. 2013) and the ahermatypic coral Carijoa riisei from Hawai'i in which green fluorescence was observed (Kahng \& Salih 2005). While reef-building corals have the capacity to produce significant quantities of FPs (Leutenegger et al. 2007), the function of FPs is unknown. As a result of ambiguous data which may be caused by the diversity of FPs and corals, hypothesized roles for the function of FPs include photoprotection (Salih et al. 2000, Roth et al. 2010, Smith et al. 2013), antioxidant activity (Mazel et al. 2003, Bou-Abdallah et al. 2006, Palmer et al. 2009a), photosynthesis enhancement (Salih et al. 2000), Symbiodinium regulation (Field et al. 2006), part of an immune response (Palmer et al. 2009b, D'Angelo et al. 2012), camouflage (Matz et al. 2006b), maintenance of color diversity (Dove et al. 2001), and attraction of free-living Symbiodinium (Hollingsworth et al. 2004). It is possible that different FPs could have different roles, particularly in distinct environments such as shallow or mesophotic habitats. Thus research on coral fluorescence in mesophotic corals may provide unique insights into the function of FPs and coral-algal physiology.

The Indo-Pacific mesophotic zone offers a remarkable opportunity to study vibrant coral reef ecosystems that are dominated by several species of reefbuilding coral Leptoseris below $60 \mathrm{~m}$ (Kahng et al. 2010, Luck et al. 2013). With the deepest in situ observation of $L$. hawaiiensis from $165 \mathrm{~m}$ at Johnston Atoll, an isolated reef in the Central Pacific (Maragos \& Jokiel 1986), these reef-building corals exemplify the paradox of photosynthetic organisms thriving in low-irradiance environments. This study focuses on coral fluorescence in dominant mesophotic-restricted corals and is part of a 'Deep Reef' research collective characterizing the biodiversity, productivity, physiology, and ecology of mesophotic Leptoseris reefs and their associated communities in Hawai'i. Because the extent of coral fluorescence is uncharacterized among species of the deep mesophotic zone, this study investigated the abundance of fluorescent morphs, the types of FPs, and the FP emission phenotypes in 4 species of mesophotic-restricted Leptoseris from 65 to $125 \mathrm{~m}$ in Hawai'i. Additionally, we explored the physiological relationship between coral fluorescence and a variety of Symbiodinium characteristics, including genotype, abundance, photosynthetic parameters, and pigment quantities, to determine if mesophotic FPs could have a role in photosynthesis. This research is the first to describe the ecology of coral fluorescence in dominant reef-building corals of the mesophotic zone and combines multiple data sets on corals and Symbiodinium from a distinctive, rarely accessible environment. Overall, these findings have significant implications for the function of mesophotic FPs in corals.

\section{MATERIALS AND METHODS}

\section{Irradiance measurements}

Irradiance attenuation profiles were obtained using a spherical underwater irradiance sensor (LICOR LI-193) corrected for underwater use connected to a data logger (LICOR LI-1400) enclosed within a PVC housing integrated with a pressure transducer to calculate depth. Measurements were taken directly over mesophotic coral reefs $\left(20^{\circ} 45.510^{\prime} \mathrm{N}, 156^{\circ} 34.503^{\prime} \mathrm{W}\right)$ in close vicinity to the corals used in this study. Measurements of PAR (400-700 nm) were taken at approximately $1 \mathrm{~m}$ intervals in the water column at midday (11:00-12:30 h) to a depth of $\sim 90 \mathrm{~m}$ during 3 clear, calm, cloudless days in the summers of 2008 and 2010. These data were used to calculate the light attenuation according to Beer's Law, which was then used to model the irradiance profile for each day. Irradiance profiles were averaged between all 6 days and the standard error at each depth was calculated.

\section{Sample collection}

Leptoseris spp. $(\mathrm{n}=48)$ were collected from reefs at 65 to $125 \mathrm{~m}$ depths in the 'Au'au Channel offshore of Olowalu, west Maui $\left(20^{\circ} 46.851^{\prime} \mathrm{N}\right.$, $156^{\circ} 40.391^{\prime}$ W), in February and March 2011 using the 'Pisces V' submersible (www.soest.hawaii. edu/HURL). The 'Au'au Channel separates the islands of Maui and Lāna'i, and has a bottom topography consisting of a gently sloping, continuous limestone bridge.

At each site, representative corals $\sim 20$ to $30 \mathrm{~cm}$ in diameter were haphazardly selected from the middle 
of a Leptoseris reef, with each collected sample separated by at least $10 \mathrm{~m}$ in distance. The entire coral or a small, triangular piece of coral (spanning from the middle to the outer edge of the coral head) was gently removed using a Schilling Titan 4 manipulator arm, and placed in individual sample containers in the sampling basket. Collected samples were kept in a darkened container at ambient in situ seawater temperatures, and processed in a darkened airconditioned laboratory (using red light headlamps with an intensity of $\sim 1 \mu \mathrm{mol}$ quanta $\mathrm{m}^{-2}$ $\mathrm{s}^{-1}$ from a distance of 40 to $50 \mathrm{~cm}$ ) onboard the R/V 'Ka'imikai-O-Kanaloa' (www.soest.hawaii.edu/UMC/ $\mathrm{cms} /$ kaimikai-o-kanaloa/) within 3 to $9 \mathrm{~h}$ of ascent. Photosynthetic characteristics were assessed with chlorophyll fluorescence measurements taken with a pulse amplitude modulated (PAM) fluorometer (Diving-PAM, Walz). Subsequently, corals were assessed for FPs by visual examination of emission phenotypes (see below) and fragmented for further subsampling. Fragments of Leptoseris spp. destined for analyses of spectral properties were maintained alive in individual aquaria at ambient in situ seawater temperatures under low irradiance levels ( 10 mol quanta $\left.\mathrm{m}^{-2} \mathrm{~s}^{-1}\right)$ and the water was changed daily, for $\leq 5 \mathrm{~d}$. At the end of the cruise, corals were packed in damp, light-proof containers and transported to the Hawai'i Institute of Marine Biology, O'ahu, for spectral measurements (see below). Fragments for host genetics, symbiont genetics, Symbiodinium abundances, and photosynthetic pigments analyses were frozen at $-80^{\circ} \mathrm{C}$ on the cruise, transported on dry ice to the University of Hawai'i at Mānoa, O'ahu, and maintained in a $-80^{\circ} \mathrm{C}$ freezer until analyzed. Data analyses were conducted with actual collection depth measurements, while in graphs, corals were grouped in roughly $10 \mathrm{~m}$ depth increments, based on sites of collection: $70 \mathrm{~m}(65-75 \mathrm{~m}, \mathrm{n}=11), 80 \mathrm{~m}(76-85 \mathrm{~m}$, $\mathrm{n}=10), 90 \mathrm{~m}(86-95 \mathrm{~m}, \mathrm{n}=9), 100 \mathrm{~m}(96-105 \mathrm{~m}$, $\mathrm{n}=6)$, and $120 \mathrm{~m}(120-125 \mathrm{~m}, \mathrm{n}=12)$.

\section{Coral and symbiont genetics}

The 48 Leptoseris spp. samples selected in this study were a subset of a more detailed host/symbiont genetic study (Pochon et al. 2015). To address the high cryptic diversity in the genus Leptoseris (Luck et al. 2013), we used the fast-evolving mitochondrial marker cox1-1-rRNA intron to assign host species following the protocol of Luck et al. (2013). Briefly, primers ZFCOXIF (forward; 5'-TCT GGT GAG CTC
TTT GGG CTC T-3') and ZFtrnar (reverse; 5'-CGA ACC CGC TTC TTC GGG GC-3') and the thermocycling conditions described in Luck et al. (2013) were used to generate an approximately $800 \mathrm{bp}$ fragment of the cox1-1-rRNA intron. For each coral sample, direct bi-directional sequences were generated using the ABI Prism Big Dye ${ }^{\mathrm{TM}}$ Terminator Cycle Sequencing Ready Reaction Kit and an ABI 3100 Genetic Analyzer (Perkin-Elmer Applied Biosystems). All sequences were compared to the sequence dataset of Luck et al. (2013) for species-level identification.

To determine symbiont genotype in each coral sample, the $1057 \mathrm{bp}$ fragment of Symbiodinium spp. COI mtDNA was PCR-amplified using primers COX1_FOR2 (forward; 5'-CCA CCA TTA TCC ACT TCT TTT A-3') and COX1_REV1 (reverse; 5'-GGC ATA ACA TTA AAT CCT AAG AA-3'), using the thermocycling conditions described in Pochon et al. (2012). To test if Symbiodinium diversity was correlated with corals with different fluorescence patterns, a subset of corals $(n=12)$ were sampled in the calyx and coenosarc for additional genotyping. PCR products were purified and sequenced directly in both directions as described above.

\section{Abundance of fluorescent morphs and characterization of fluorescence emission phenotypes}

Coral fluorescence was examined by using a blue light source $\left(6 \mathrm{~mW} \mathrm{~cm}{ }^{-2}, \sim 450 \mathrm{~nm}\right.$, NightSea) and yellow barrier filter $(\geq 500 \mathrm{~nm}$ longpass, NightSea) onboard the research vessel following PAM measurements. Presence and absence of green/ cyan fluorescence was observed in the coenosarc and/or oral disc. Usual fluorescence phenotypes were defined as coenosarc (includes coenosarc and oral disc fluorescence), oral disc only, or nonfluorescent.

\section{Spectral properties of coral fluorescent pigments and Symbiodinium pigments}

Live coral tissue was removed using $0.2 \mu \mathrm{m}$ filtered seawater and a Waterpik ${ }^{\circledR}$. A portion of the whole coral homogenate was centrifuged to obtain coral and Symbiodinium enriched fractions. Excitation and emission spectra of the whole coral homogenate (coral and symbiont), the coral fraction, and the Symbiodinium fraction were measured using a 
fluorescence spectrofluorometer (SpectraMax M2, Molecular Devices). Samples (300 $\mu \mathrm{l})$ were measured in a black 96-well microtiter plate. To characterize FPs, emission scans were conducted with an excitation beam of $450 \pm 9 \mathrm{~nm}$ and emission was followed from 475 to $700 \mathrm{~nm}$ ( $3 \mathrm{~nm}$ increments) on the coral fraction and coral homogenate. FP excitation was scanned from 400 to $480 \mathrm{~nm}$ ( $3 \mathrm{~nm}$ increments) with an emission of $501 \pm 9 \mathrm{~nm}$. Excitation and emission spectra were normalized to the highest peak in each scan. FPs were classified according to Alieva et al. (2008): fluorescence with emission peaks from 485 to $490 \mathrm{~nm}$ and excitation and emission peaks with wide $(\sim 55 \mathrm{~nm})$ full width at half maximum (FWHM) were classified as CFP, and fluorescence with emission peaks $\geq 500 \mathrm{~nm}$ and excitation and emission peaks with narrow FWHM ( $\leq 35 \mathrm{~nm}$ ) were classified as GFP.

To characterize photosynthetic pigments, an excitation scan was conducted from 400 to $650 \mathrm{~nm} \mathrm{(3}$ $\mathrm{nm}$ increments) at an emission of $680 \pm 9 \mathrm{~nm}(\mathrm{chl} \mathrm{a})$ on whole-cell Symbiodinium in the Symbiodinium enriched fraction and in the coral homogenate. Spectra were normalized to the highest peak of each scan. One photosynthetic pigment excitation spectrum was excessively noisy and was smoothed with a moving average prior to analyses (Fig. S1 in the Supplement at www.int-res.com/articles/suppl/ m521p063_supp.pdf).

\section{PAM fluorometry}

Upon collection, corals were maintained in seawater in the dark and at ambient in situ temperatures for 3 to $9 \mathrm{~h}$ prior to measurements. Bio-optical measurements were collected using a Diving-PAM fluorometer (Walz). A $2 \mathrm{~cm}$ long piece of black tubing (1 $\mathrm{cm}$ diameter) was attached to the PAM fiber optic sensor to standardize the area measured and to ease placement of the sensor onto the coral surface. Actinic PAR values from the PAM with the fiber optic sensor tubing were calibrated with a cosine underwater quantum sensor (LICOR LI192SA) and data logger (LICOR LI-1400). To account for potential spatial variation in coral physiology, 10 measurements of maximum quantum yield of photosystem II $\left(F_{\mathrm{v}} / F_{\mathrm{m} i} F_{\mathrm{v}}=\right.$ variable fluorescence and $F_{\mathrm{m}}=$ maximum fluorescence; Ralph \& Gademann 2005) were taken from haphazardly selected, spatially separated points on the coral tissue surface, and averaged for each sample. Rapid light response curves (RLCs) were used to measure photosynthetic performance under different light levels according to Ralph \& Gademann (2005). RLC irradiances were set to match the local environment, and increased from 0 to $75 \mu$ mol photons $\mathrm{m}^{-2} \mathrm{~s}^{-1}$ in 8 steps. The average electron transport rates by actinic irradiance intensities (ETRs) for each algal sample were fit to a 3-parameter nonlinear model as described by Frenette et al. (1993). RLC data were used to estimate the relative maximum electron transport rate $\left(\mathrm{rETR}_{\max }\right), \alpha$ (initial slope of the RLC), and the minimum saturating irradiance for photosynthesis $\left(E_{\mathrm{k}}\right)$. We used the relative measure of rETR because the exact absorbance of the coral is unknown, and likely varies by species and depth-related skeletal phenotypic differences. Curves were fitted using the Regression Wizard in Sigmaplot (v. 12.0, SPSS), and estimates of $\mathrm{rETR}_{\max }, \alpha$, and $E_{\mathrm{k}}$ were used for analyses. In all samples, the model fit the data well with an $\mathrm{R}^{2}$ of $0.97 \pm 0.01$ (mean $\pm \mathrm{SEM}$ ).

\section{Symbiodinium abundances and pigments}

Flow cytometry was used to determine symbiont cell counts according to Apprill et al. (2007). Briefly, the coral tissue was removed from the coral skeleton using a Waterpik ${ }^{\circledR}$ and filtered seawater, then blended, centrifuged, and washed repeatedly until free of host material, and resuspended in filtered seawater with $1 \%$ paraformaldehyde. Samples were analyzed using a Beckman-Coulter XL flow cytometer with a $15 \mathrm{~mW}$ argon ion laser providing excitation at $488 \mathrm{~nm}$. The flow cytometer was interfaced with an Orion syringe pump for quantitative sample analysis using a $3 \mathrm{ml}$ syringe delivering $100 \mu \mathrm{l}$ of suspended cells at a flow rate of $50 \mu \mathrm{min}^{-1}$ for measurement of fluorescence emission of chlorophyll (630 nm dichroic filter, $680 \mathrm{~nm}$ bandpass filter), as well as forward and side scatter signals. Symbiodinium abundances were standardized to the coral surface area measured with the aluminum foil method (Marsh 1970) and to grams of ash-free dry weight (AFDW).

Photosynthetic pigments were analyzed using HPLC. Sample preparation was carried out following Padilla-Gamiño et al. (2013). Briefly, coral homogenate containing symbionts were filtered and extracted in $100 \%$ acetone. Pigments were analyzed by a Varian 9012 HPLC system equipped with a Varian 9300 autosampler, a Timberline column heater $\left(26^{\circ} \mathrm{C}\right)$, and a Waters Spherisorb ${ }^{\circledR} 5 \mu \mathrm{m}$ ODS-2 analytical column $(4.6 \times 250 \mathrm{~mm})$ and corresponding guard cartridge $(7.5 \times 4.6 \mathrm{~mm})$ following Bidigare et al. (2005). Pigments were detected with a ThermoSeparation Prod- 
ucts UV2000 detector $\left(\lambda_{1}=436, \lambda_{2}=450\right)$. Peak identity was determined by comparing retention times of pure standards with those of extracts prepared from algal cultures of known pigment composition. Pigments were standardized per cell and to coral surface area measured as above (Marsh 1970).

\section{Data analyses}

Statistical analyses were conducted using JMP version 8.0 (SAS Institute). The correlation between depth (actual depth) and FPs was assessed using the nonparametric Spearman's rho $(\rho)$. Two-tailed $t$-tests were used to compare the Symbiodinium physiology and abundance data from nonfluorescent and fluorescent corals. Because Symbiodinium data sets were collected primarily from symbionts in the coenosarc, fluorescence emission was classified as: fluorescent corals (coenosarc and oral disc fluorescent) and nonfluorescent corals (oral disc only fluorescent and nonfluorescent). Two-way ANOVAs were conducted for the 2 factors depth (actual depth) and coral fluorescence for each parameter, and none had significant interaction effects $(p>0.05)$; therefore, depths were combined for $t$-tests of the effects of fluorescence on symbiont physiology and abundance. Data were tested for assumptions of normality and transformed prior to analyses if appropriate. Data were also tested for equal variances (Levene's test) and when necessary, unequal $t$-tests were used. Statistical differences were significant at the $\alpha<0.05$ level. Data are represented as mean \pm SEM.

\section{RESULTS}

\section{Genetic diversity of Leptoseris spp. and Symbiodinium}

The detailed phylogenetic analysis of the 48 cox11-rRNA mtDNA coral sequences indicated unambiguous correspondence for 4 species of Leptoseris: $L$. scabra (clade VII, $\mathrm{n}=11$ ), L. tubulifera (clade Ia, $\mathrm{n}=$ 11), L. sp. 1 (clade Ia, $\mathrm{n}=14$ ), and L. hawaiiensis (clade $\mathrm{Ib}, \mathrm{n}=11$ ) (clades as indicated in Luck et al. 2013 and Pochon et al. 2015). Host genetics were not conducted on 1 sample (L76). GenBank accession numbers for cox1-1-rRNA mtDNA sequences can be found in Table S1 in the Supplement at www.intres.com/articles/suppl/m521p063_supp.pdf.

Symbiodinium COI sequences grouped into 3 unambiguous mitochondrial haplotypes (COI-1, n =
11; COI-2, $\mathrm{n}=27$; and COI-3, $\mathrm{n}=10$ ), all belonging to Symbiodinium clade C but different from the previously published COI sequences produced in Pochon et al. (2012) for Symbiodinium C1 (4-6 bp differences), C15 (3-7 bp), C90 (13-14 bp), and C91 (14-17 bp) (data not shown). Haplotypes COI-1, COI2 , and COI-3 differed from each other by 3 to $7 \mathrm{bp}$ changes. No mixed Symbiodinium genotypes were found within individual coral colonies, regardless of location on the coral (Table S2 in the Supplement). GenBank accession numbers for COI-1, COI-2, and COI-3 are HG942426, HG942427, and HG942428, respectively.

\section{Ecology of FPs in Leptoseris spp.}

Over the habitat of the Leptoseris spp. mesophotic reef ecosystem, irradiance ranged from $68.7 \pm 6.3$ $\mu \mathrm{mol}$ quanta $\mathrm{m}^{-2} \mathrm{~s}^{-1}$ at $65 \mathrm{~m}$ to $6 \pm 0.9 \mu \mathrm{mol}$ quanta $\mathrm{m}^{-2} \mathrm{~s}^{-1}$ at $125 \mathrm{~m}$ (Fig. 1a), which represented $2.69 \%$ and $0.23 \%$ of surface PAR irradiance respectively. Most corals from the entire depth range (65-125 m) exhibited cyan/green fluorescence emission (64$89 \%$; Fig. 1a); fluorescent and nonfluorescent corals were found at every depth sampled. Two FPs were responsible for the cyan/green fluorescence: the higher-energy CFP had peak excitation at $424 \mathrm{~nm}$ (FWHM > $54 \mathrm{~nm}$ ) and peak emission at $490 \mathrm{~nm}$ $(\mathrm{FWHM}>54 \mathrm{~nm})(\mathrm{n}=16$; Fig. $1 \mathrm{~b})$, and the lowerenergy GFP had peak excitation at $478 \mathrm{~nm}$ (FWHM > $18 \mathrm{~nm}$ ) and peak emission at $502 \mathrm{~nm}$ (FWHM = $\sim 30 \mathrm{~nm})(\mathrm{n}=9$; Fig. 1c). Two corals (collected from 86-95 m) produced both CFP and GFP.

Technical limitations arose in the precise estimation of the excitation peak of GFP; the measurements did not extend above $480 \mathrm{~nm}$. However, we consider that it was likely that the measured GFP excitation peak $(478 \mathrm{~nm})$ was very close to the true peak because the Stokes shift of GFP in corals is $\sim 9-24 \mathrm{~nm}$ (Alieva et al. 2008). Additionally, some of the FWHM were also not precisely measured because the FWHM was out of the range of the measurement. However, the data clearly showed that CFP had much wider excitation and emission spectra compared to GFP, which is typical of these types of FPs. As a negative control, nonfluorescent corals lacked any FP peaks in their spectra $(\mathrm{n}=13)$. For some corals with low fluorescence, such as visual fluorescence in the oral disc only $(n=8)$ and weak coenosarc fluorescence $(\mathrm{n}=1)$, it was not possible to obtain FP spectra, perhaps due to low instrument sensitivity. Additionally, one coral died prior to spectral analysis. 

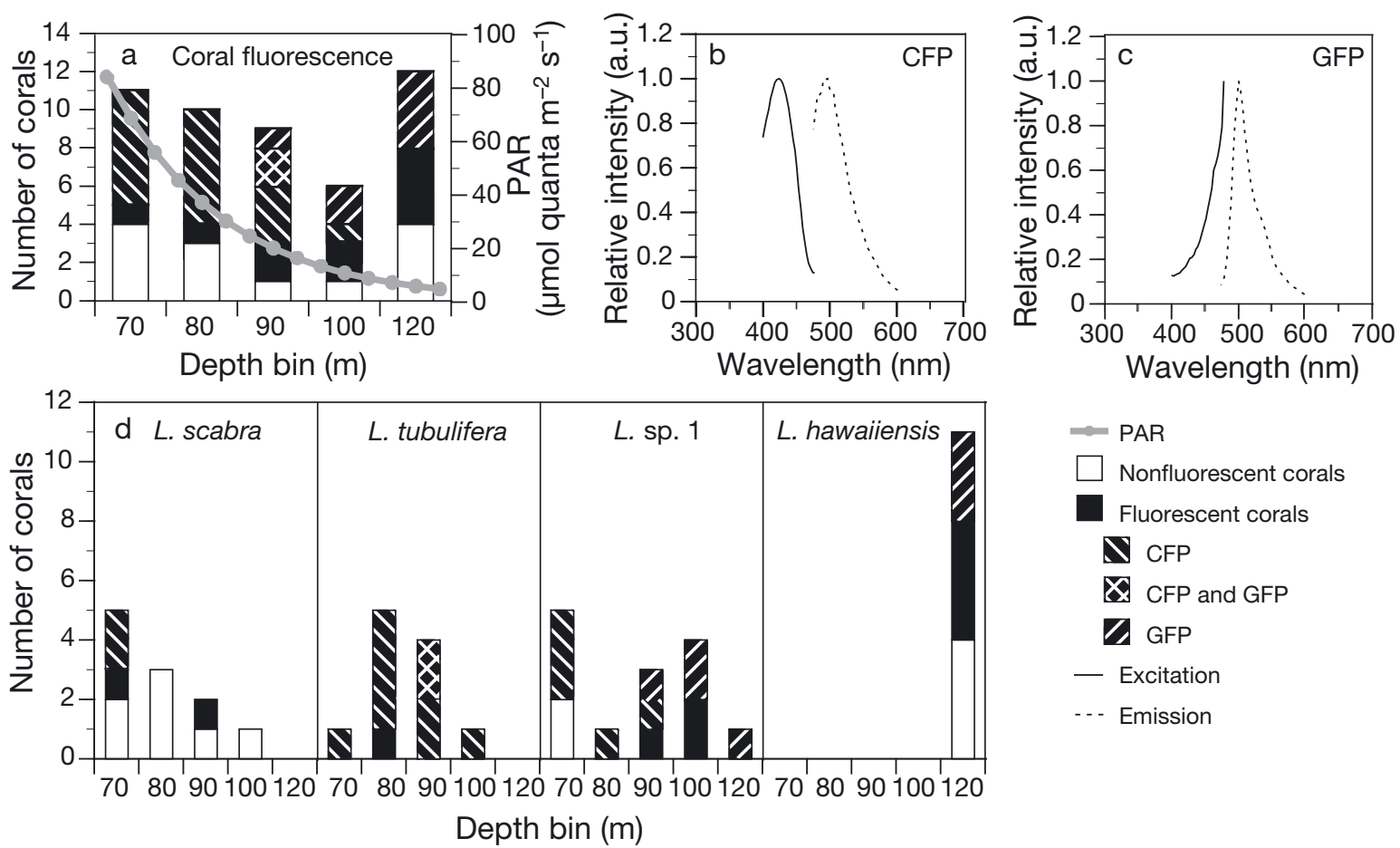

Fig. 1. Ecology of coral fluorescent proteins (FPs) in Leptoseris spp. collected at 65 to $125 \mathrm{~m}$. (a) Fluorescent and nonfluorescent corals by depth plotted with photosynthetically active radiation (PAR) levels. A cyan fluorescent protein (CFP) and a green fluorescent protein (GFP) were identified from Leptoseris spp. (b,c) FP spectral characteristics showing excitation spectra with emission peak at $501 \mathrm{~nm}$ and emission spectra with $450 \mathrm{~nm}$ excitation. The excitation peaks were 424 and $478 \mathrm{~nm}$ for CFP and GFP, respectively, and the emission peaks were 490 and $502 \mathrm{~nm}$, respectively. (d) Fluorescent corals and nonfluorescent corals by depth and Leptoseris spp. Solid black bars represent fluorescent corals with unidentified FP type

FP type was significantly correlated with depth among all the species $(\rho=0.71, \mathrm{p}<0.0001, \mathrm{n}=27$; Fig. 1a) and within the species L. sp. $1(\rho=0.80, \mathrm{p}<$ $0.05, \mathrm{n}=9$; Fig. 1d). CFP was prevalent in shallower corals $(65-85 \mathrm{~m})$, the GFP was dominant in deeper corals (96-125 m), and the FPs overlapped at middle depths (86-95 m). The 4 species of Leptoseris all contained fluorescent and nonfluorescent individuals (Fig. 1d). L. scabra had the lowest proportion of fluorescent morphs $(36 \% ; \mathrm{n}=11)$, while $100 \%$ of $L$. tubulifera were fluorescent $(\mathrm{n}=11) . L$. sp. $1(\mathrm{n}=14)$ and $L$. hawaiiensis $(\mathrm{n}=11)$ had $86 \%$ and $64 \%$ of corals with fluorescence, respectively (Fig. 1d). L. scabra only produced the CFP; $L$. tubulifera mostly produced the CFP, with 2 individuals exhibiting both the CFP and the GFP; L. sp. 1 produced both the CFP and the GFP; and L. hawaiiensis only produced the GFP (Fig. 1d). L. scabra was collected mostly from the shallower sites $(65-85 \mathrm{~m})$ and less with increasing depth$_{i}$ L. tubulifera was collected primarily from mid-range depths $(76-95 \mathrm{~m})$; L. sp. 1 was collected over the entire depth range $(65-125 \mathrm{~m})$; and $L$. hawaiiensis was only collected from the deepest range (120-125 m) (Fig. 1d).

\section{FP emission phenotypes in Leptoseris spp.}

Mesophotic corals were observed with FP emission present in the coenosarc (includes oral disc) (Fig. 2a), in the oral disc only (Fig. 2b), or without coral fluorescence (Fig. 2c). In areas of the corals without cyan/green FP emission, the red fluorescence from Symbiodinium photosystem II was visible (Fig. 2b,c). L. tubulifera was only observed with coenosarc fluorescence emission phenotype, while $L$. Scabra, $L$. sp. 1 , and $L$. hawaiiensis contained both coenosarc and oral disc only fluorescence emission phenotypes (Fig. 2d). The coenosarc fluorescence emission phenotype resulted from the CFP in $L$. scabra, GFP in $L$. hawaiiensis, and both CFP and GFP in L. tubulifera and $L$. sp. 1. In contrast, the oral disc fluorescence only phenotype in L. scabra and L. sp. 1 resulted from only CFP. However, the number of samples with fluorescence emission only from the oral disc was low $(\mathrm{n}=3)$, resulting in unclassified FP type(s) for most oral disc only samples $(n=8)$. Rare coral fluorescence emission phenotypes included a bright localization of fluorescence spots $(n=7)$ in either random placement (Fig. S2a in the Supplement) or striations (Fig. S2b in 

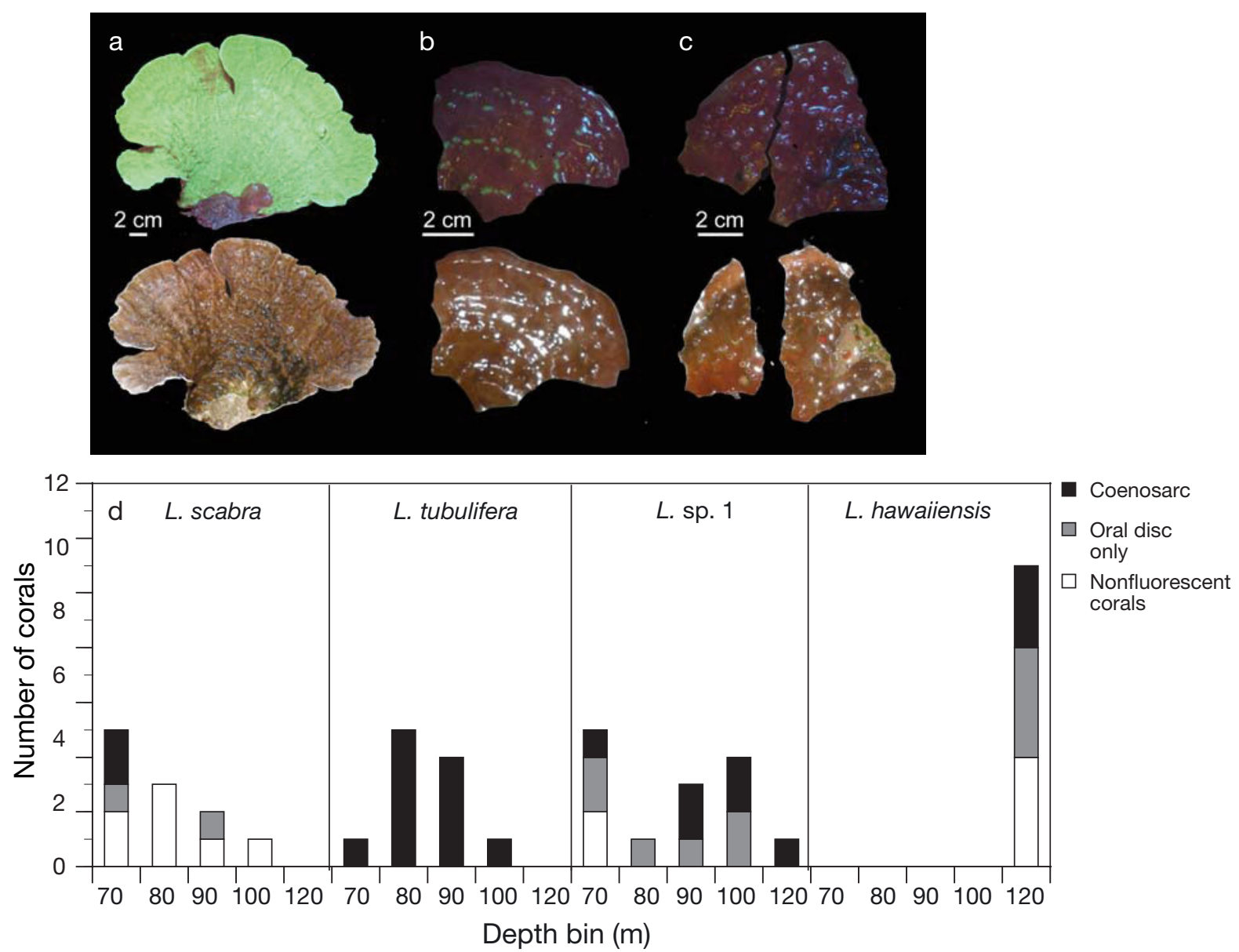

Fig. 2. Coral fluorescent protein localization in Leptoseris spp. Common patterns observed: (a) coral fluorescence in the coenosarc and oral disc, (b) coral fluorescence in the oral disc only, and (c) no coral fluorescence. Leptoseris spp. were imaged using a camera (Olympus C-5050) with a blue excitation light (Inon Z-240 strobe with NightSea blue filter, $450 \mathrm{~nm}$ ) and barrier filter ( $\geq 500 \mathrm{~nm}$ longpass, NightSea) on the lens of the camera for fluorescence (top row) and under white light (Inon Z-240 strobe) (bottom row). (d) Common fluorescence localization patterns by species and depth
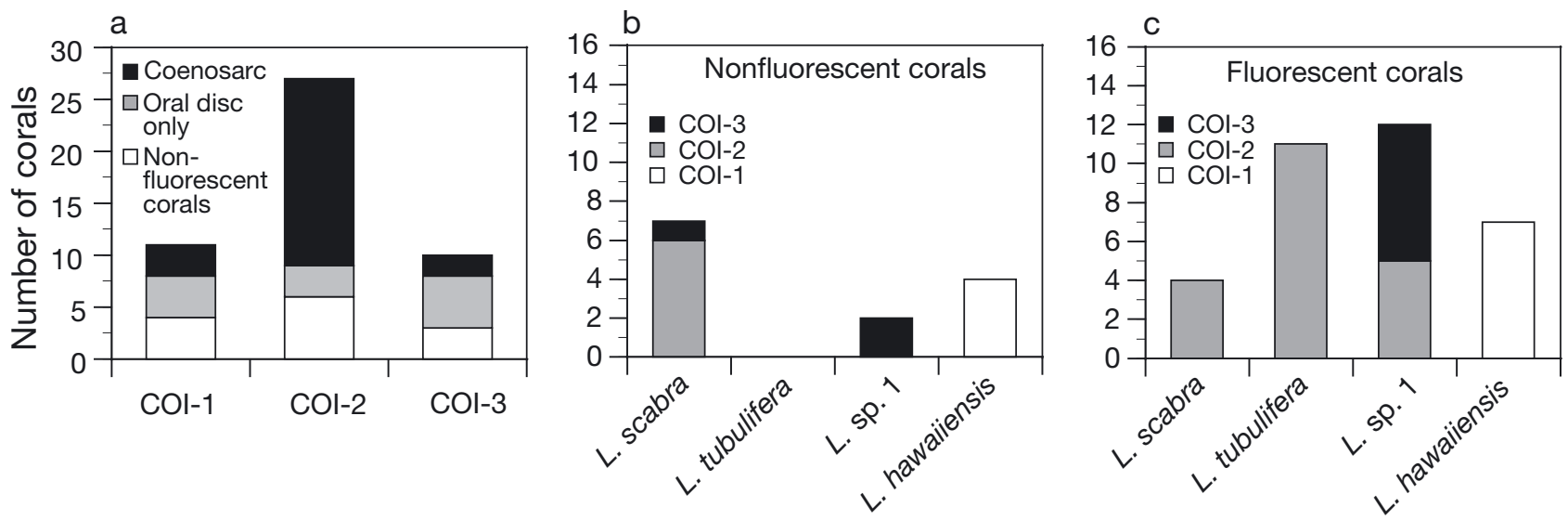

Fig. 3. Fluorescence patterns and clade C Symbiodinium spp. in Leptoseris spp. (a) Corals with all 3 Symbiodinium haplotypes COI-1, COI-2, and COI-3 and with either coenosarc fluorescence, oral disc only fluorescence, or no fluorescence. (b,c) Symbiodinium haplotypes COI-1, COI-2, and COI-3 in nonfluorescent and fluorescent corals 
Table 1. Comparison of Symbiodinium characteristics between fluorescent (coenosarc fluorescence) vs. nonfluorescent Leptoseris spp. (includes nonfluorescent and oral disc only fluorescent corals), including means and $t$-tests (2-tailed). rETR $\mathrm{max}_{\text {: }}$ relative maximum electron transport rate, $\alpha$ : initial slope of the rapid light response curve, $E_{\mathrm{k}}$ : minimum saturating irradiance for photosynthesis, $F_{\mathrm{v}}$ : variable fluorescence, $F_{\mathrm{m}}$ : maximum fluorescence, AFDW: ash-free dry weight

\begin{tabular}{|c|c|c|c|c|c|}
\hline \multirow[t]{2}{*}{ Parameter } & \multicolumn{2}{|c|}{ Mean \pm SEM } & \multicolumn{3}{|c|}{$t$-test } \\
\hline & Fluorescent & Nonfluorescent & $t$-ratio & $\mathrm{p}$ & $\mathrm{df}$ \\
\hline $\mathrm{rETR}_{\max }\left(\mu \mathrm{mol}\right.$ electrons $\left.\mathrm{m}^{-2} \mathrm{~s}^{-1}\right)$ & $3.70 \pm 0.33$ & $3.67 \pm 0.38$ & 0.1 & 0.95 & 33 \\
\hline$\alpha(\mu \mathrm{mol}$ electrons $)$ & $0.25 \pm 0.01$ & $0.27 \pm 0.02$ & -0.8 & 0.41 & 33 \\
\hline$E_{\mathrm{k}}\left(\mu \mathrm{mol}\right.$ photons $\left.\mathrm{m}^{-2} \mathrm{~s}^{-1}\right)$ & $14.19 \pm 0.73$ & $13.40 \pm 0.82$ & 0.7 & 0.47 & 33 \\
\hline Maximum quantum yield $\left(F_{\mathrm{v}} / F_{\mathrm{m}}\right)$ & $0.66 \pm 0.01$ & $0.67 \pm 0.01$ & -0.5 & 0.65 & 35 \\
\hline Symbiodinium density (cells $\mathrm{cm}^{-2}$ ) & $5.6 \times 10^{5} \pm 0.4 \times 10^{5}$ & $5.5 \times 10^{5} \pm 0.5 \times 10^{5}$ & 0.3 & 0.75 & 45 \\
\hline Symbiodinium density (cells g ${ }^{-1}$ AFDW) & $1.2 \times 10^{10} \pm 0.1 \times 10^{10}$ & $1.2 \times 10^{10} \pm 0.1 \times 10^{10}$ & -0.3 & 0.77 & 45 \\
\hline Chl a (pg cell-1) & $19.5 \pm 1.5$ & $16.9 \pm 1.1$ & 1.4 & 0.17 & 45 \\
\hline Chl $C_{2}\left(\mathrm{pg} \mathrm{cell}^{-1}\right)$ & $2.7 \pm 0.2$ & $2.2 \pm 0.1$ & 1.8 & 0.09 & 45 \\
\hline Peridinin $\left(\mathrm{pg}\right.$ cell $\left.{ }^{-1}\right)$ & $8.7 \pm 0.6$ & $7.7 \pm 0.5$ & 1.3 & 0.20 & 45 \\
\hline Diadinoxanthin + diatoxanthin $\left(\mathrm{pg} \mathrm{cell}{ }^{-1}\right)$ & $2.5 \pm 0.2$ & $2.1 \pm 0.1$ & 1.7 & 0.10 & 45 \\
\hline$\beta$-carotene (pg cell ${ }^{-1}$ ) & $0.46 \pm 0.04$ & $0.38 \pm 0.02$ & 1.8 & 0.07 & 45 \\
\hline Chl a $\left(\mathrm{ng} \mathrm{cm}^{-2}\right)$ & $355 \pm 36$ & $293 \pm 24$ & -0.7 & 0.48 & 45 \\
\hline $\mathrm{Chl} C_{2}\left(\mathrm{ng} \mathrm{cm}^{-2}\right)$ & $49 \pm 5$ & $39 \pm 3$ & 1.7 & 0.10 & 45 \\
\hline Peridinin $\left(\mathrm{ng} \mathrm{cm}^{-2}\right)$ & $160 \pm 17$ & $132 \pm 11$ & 1.4 & 0.17 & 45 \\
\hline Diadinoxanthin + diatoxanthin $\left(\mathrm{ng} \mathrm{cm}^{-2}\right)$ & $46 \pm 4$ & $37 \pm 3$ & 1.7 & 0.10 & 45 \\
\hline$\beta$-carotene $\left(\mathrm{ng} \mathrm{cm}^{-2}\right)$ & $8 \pm 1$ & $8 \pm 1$ & 1.9 & 0.06 & 45 \\
\hline $\mathrm{Chl} \mathrm{C}_{2}: \mathrm{chl} a$ & $0.14 \pm 0.01$ & $0.13 \pm 0.01$ & 1.1 & 0.27 & 45 \\
\hline Peridinin:chl $a$ & $0.45 \pm 0.01$ & $0.45 \pm 0.01$ & -0.9 & 0.40 & 45 \\
\hline
\end{tabular}

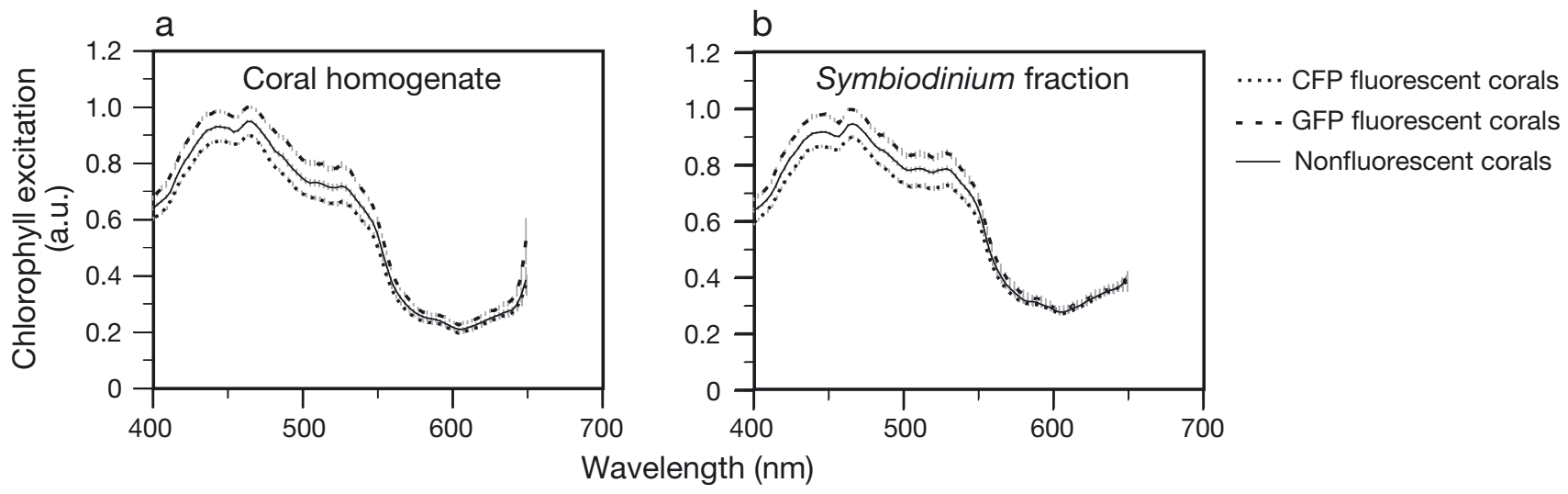

Fig. 4. Leptoseris spp. and Symbiodinium spp. Normalized photosynthetic pigment excitation spectra from Leptoseris spp. (a) The whole coral homogenate and (b) the Symbiodinium fraction (mean \pm SEM). For better visualization of the spectra, samples from corals with the cyan fluorescent protein (CFP) were normalized to $90 \%(n=12)$, samples from corals with the green fluorescent protein (GFP) normalized to100\% $(\mathrm{n}=7)$, and samples from corals with no coral fluorescence normalized to $95 \%(n=13)$

the Supplement) in corals with coenosarc fluorescence in L. tubulifera and L. sp. 1.

\section{Leptoseris spp. fluorescence and Symbiodinium}

Three clade C haplotypes of Symbiodinium were identified from all corals both with and without fluorescence emission (Fig. 3a). The proportion of corals with any type of visual fluorescence and haplotype COI-1 $(n=11)$, COI-2 $(n=27)$, and COI-3 $(n=10)$ was
$64 \%, 78 \%$, and $70 \%$ respectively. Corals that produced the CFP hosted COI-2 and COI-3 haplotypes, while corals that produced the GFP hosted all 3 haplotypes. The corals that produced both the CFP and GFP hosted the COI-2 haplotype. L. scabra and L. sp. 1 hosted 2 types of Symbiodinium (COI-2 and COI$3)$, while $L$. tubulifera only hosted COI- 2 , and $L$. hawaiiensis only hosted COI-1 (Fig. 3b,c). Nonfluorescent L. scabra hosted both COI-2 and COI-3, while fluorescent L. scabra only hosted COI-2. In contrast, nonfluorescent L. sp. 1 hosted COI-3 and 
fluorescent $L$. sp. 1 hosted both COI-2 and COI-3. The subset of corals with additional Symbiodinium genotyping from the oral disc and coenosarc had the same haplotype in all locations regardless of haplotype type, coral species, fluorescence emission patterns, or type of FP (Table S2 in the Supplement).

Corals with and without fluorescence emission had Symbiodinium with similar physiological characteristics (Table 1). There were no significant differences among Symbiodinium abundance, $\operatorname{rETR}_{\max }, \alpha, E_{\mathrm{k}}$, $F_{\mathrm{v}} / F_{\mathrm{m}}$, chl a per cell or per $\mathrm{cm}^{2}$, chlorophyll $C_{2}\left(\mathrm{chl} C_{2}\right)$ per cell or per $\mathrm{cm}^{2}$, peridinin per cell or per $\mathrm{cm}^{2}$, xanthophyll pool (diadinoxanthin + diatoxanthin) per cell or per $\mathrm{cm}^{2}, \beta$-carotene per cell or per $\mathrm{cm}^{2}$, chl $C_{2}$ :chl a ratio, and peridinin:chl a ratio (Table 1 ). The excitation spectrum of photosynthetic pigments peaked at $\sim 465 \mathrm{~nm}$, with a secondary peak at $\sim 450 \mathrm{~nm}$ (chl $a$ and $C_{2}$ ), and there was a shoulder from 500-550 nm (peridinin) (Fig. 4; cf. Bricaud et al. 2004). The excitation spectra of photosynthetic pigments in both the whole coral homogenate (includes Symbiodinium) and Symbiodinium fraction were similar, and the spectra were similar among corals with CFP ( $\mathrm{n}=$ 12), GFP ( $n=7)$, and no fluorescence $(n=13)$ (Fig. 4).

\section{DISCUSSION}

This study combined data on visual and spectral coral fluorescence, host genetics, symbiont genetics, symbiont abundances, photosynthetic characteristics, and photosynthetic pigment concentrations to provide a thorough analysis on a unique understudied environment, and has implications for the function of FPs in corals. Specifically, this study focused on coral FPs in several species of mesophoticrestricted Leptoseris, the dominant reef-building coral in the extreme low-irradiance ecosystem in the Hawaiian Archipelago.

\section{Coral fluorescence in the mesophotic zone}

Coral fluorescence was ubiquitous in the Hawaiian mesophotic zone; it was observed in all 4 investigated species of Leptoseris and over the entire sampled depth range (65-125 m). Overall, 73\% of corals sampled were fluorescent, which is slightly lower than reports for shallow coral reef flats on the Great Barrier Reef, Australia (Salih et al. 2000). To our knowledge, the prevalence of coral fluorescence from deep (>60 m) mesophotic reefs has not previously been explored. Furthermore, we demonstrate that fluorescent and nonfluorescent morphs cooccurred at mesophotic depths, as reported for shallow corals in the Great Barrier Reef (Salih et al. 2000). The mesophotic cyan/green fluorescence emission of Leptoseris spp. is consistent with the principal fluorescence emission of shallower corals in the Caribbean (10-60 $\mathrm{m}$ in Vermeij et al. 2002, 3-30 $\mathrm{m}$ in Mazel et al. 2003) and the Great Barrier Reef (1-30 m in Gruber et al. 2008), suggesting that CFP and GFP may play a highly conserved role in the physiology of this coral-algal association. Fluorescence emission phenotypes found in this study including fluorescence over the entire coral or isolated to the oral disc is also consistent with what has been observed in shallow corals (Gruber et al. 2008). It is important to acknowledge that this study may have been biased towards CFP and GFP and methodologically unable to detect RFPs. However, because of the broad spectrum of excitation light and longpass characteristics of the filters used in this study, RFPs could have been observed as they had in other species of corals (M. S. Roth pers. obs.), but were not. Additionally, RFPs are much less common than CFP and GFP in shallow corals (Gruber et al. 2008). In sum, this study provides the first ecological characterization of FPs in a deep mesophotic zone.

Deep mesophotic zones are low-irradiance environments that are enriched in blue wavelengths due to spectral attenuation (Kirk 1994). At $70 \mathrm{~m}$ in the nearby Kalohi Channel, the blue spectral region $(\sim 410-480 \mathrm{~nm})$ is nearly $20 \%$ of surface irradiance (Kahng et al. 2012). The present study found that mesophotic Leptoseris spp. express 2 FPs with different spectral characteristics: CFP $\left(\lambda_{\text {ex }}=424 \mathrm{~nm}, \lambda_{\text {em }}=\right.$ $490 \mathrm{~nm})$ and $\operatorname{GFP}\left(\lambda_{\mathrm{ex}} \approx 478 \mathrm{~nm}, \lambda_{\mathrm{em}}=502 \mathrm{~nm}\right)$. Strikingly, CFP was dominant in corals at shallower depths (65-85 m), while the GFP prevailed in corals at deeper depths from 96-125 m. In the middle region (86-95 $\mathrm{m}$ ), both CFP and GFP were equally present in corals. CFP and GFP are correlated with depth among all the coral species as well as within species, and the FPs appear to absorb the predominant wavelengths of PAR present at the sampled depths. The wavelengths of PAR that excite GFP are enriched in deeper waters as compared to the spectral regions that excite CFP (Mass et al. 2010). There is some precedence for changes in types of FPs based on habitat. In species of the Caribbean coral Madracis, numbers of fluorescent color morphs decrease from 10 to $60 \mathrm{~m}$ depth, yet green fluorescence emission is observed over the sampled depth range (Vermeij et al. 2002). In the Indo-Pacific coral Seriatopora hystrix, swimming larvae synthesize 2 
GFPs, while the benthic adults produce a CFP, and these 2 life history stages occupy different habitats with distinct irradiance environments (Roth et al. 2013). Overall, our finding of 2 types of FPs along the depth gradient among congeners and conspecifics in the mesophotic zone fits well with other studies in shallow systems, but has never been observed over these depth zones of 65 to $125 \mathrm{~m}$.

Previous studies have also shown that corals can also vary the amount of FPs within their tissues in response to changes in environmental and physiological conditions (D'Angelo et al. 2008, Roth et al. 2010, Roth \& Deheyn 2013). However, in shallow Caribbean corals $(3-30 \mathrm{~m})$, there is no correlation between depth and GFP abundance in Montastrea cavernosa and M. faveolata (Mazel et al. 2003). Gene expression of $M$. cavernosa (8-24 m) suggests that 1 or possibly 2 GFPs are inversely related with depth, but 5 other GFPs are not correlated with depth (Kao et al. 2007). FP gene expression can change dynamically in response to environmental conditions in shallow corals and FP transcription is most regulated by blue light rather than red or green light (D'Angelo et al. 2008). Additionally, the abundance of FPs within corals rapidly decreases in response to both cold and heat stress (Roth \& Deheyn 2013). Future studies should quantify the FP abundance and gene expression in mesophotic corals from a variety of species and depths, as well as compare CFP and GFP genes from shallow and mesophotic corals to determine possible differences or similarities.

The similarity in gross morphology of Leptoseris spp. and the high morphological plasticity within species makes it difficult to separate species both while viewing corals from the submersible as well as when handling the samples in the laboratory. In this study, genetics revealed 4 species of Leptoseris ( $L$. scabra, L. tubulifera, L. sp. 1, and L. hawaiiensis), each with distinct fluorescence patterns. The cyan/ green fluorescence was localized in the coenosarc in all species, but only L. scabra, L. sp. 1, and L. hawaiiensis exhibited the oral disc only phenotype. The most divergent species in our study, L. scabra (Luck et al. 2013), had the lowest abundance of fluorescent corals (36\%) and only produced CFP. It is intriguing to ask why L. scabra has a much lower abundance of fluorescence, and it may suggest that their photophysiology is different from the other species with less selective pressure for fluorescence. L. tubulifera and $L$. sp. 1 , which were the most closely related (Luck et al. 2013), had the highest abundances of fluorescent corals $(100 \%$ and $86 \%$ respectively) and produced CFP and GFP. All colonies of L. tubulifera were fluorescent over their entire surface, suggesting that fluorescence may have an adaptive value in this species. Colonies of L. hawaiiensis, which were only located at the deepest sampled depths (120-125 m), were commonly fluorescent $(64 \%)$ and only produced GFP. Corals can quickly regulate FP transcription and concentration on short time scales in response to changes in their environment and stress (D'Angelo et al. 2008, Roth et al. 2010, Roth \& Deheyn 2013). Thus, in species where fluorescent morphs are highly abundant, weakly fluorescence or nonfluorescent morphs could indicate a different physiological state. Coral fluorescence has also been noted in species of shallow Leptoseris and mesophotic GFP emission has similar emission to GFP from the Caribbean coral Leptoseris cucullata collected from $25 \mathrm{~m}$ and often shallower (Mazel et al. 2003, C. H. Mazel pers. comm.).

Because FPs are part of the photophysiology of the coral-algal symbiosis, this study also investigated a large number of Symbiodinium characteristics. To our knowledge, this is the first study to show that Symbiodinium genotype does not have any relationship with coral fluorescence. Additionally, if the coral is fluorescent, the genotype of Symbiodinium does not affect the fluorescence emission phenotype. Symbiodinium density was highly variable, and no significant differences were observed with corals that were fluorescent or nonfluorescent. Similarly, a study of shallow corals showed no overlap between the distribution of FPs and Symbiodinium (Gruber et al. 2008). Photosynthetic pigments absorb different wavelengths, with the primary peak of chl a absorbing higher-energy light than chl $C_{2}$, which is then absorbing higherenergy light than peridinin (Bricaud et al. 2004). Peridinin is an important light-harvesting pigment in Symbiodinium that extends the spectral range of light harvested for photosynthesis into green wavelengths (Bricaud et al. 2004). The peak absorbance of peridinin most closely aligns with peak emissions of CFP and GFP. In this study, the concentrations of chl $a_{\text {, }}$ $\mathrm{chl} C_{2}$ and peridinin were similar between fluorescent and nonfluorescent corals, as were the ratios of $\mathrm{chl} \mathrm{C}_{2}$ : $\mathrm{chl} a$ and peridinin:chl $a$. The chlorophyll excitation spectra from corals with GFP, CFP, and no fluorescence were similar in the coral homogenate, the Symbiodinium fraction, and between the two fractions. The FP peak emissions (490 and $502 \mathrm{~nm}$ ) do not overlap with the absorbance peaks of chlorophylls (440$465 \mathrm{~nm}$ ), but rather the shoulder of the photosynthetic pigment excitation and the peak absorbance of peridinin (490-510 nm). It may be possible that the relationship between FPs and photosynthesis was dis- 
rupted when the coral tissue was removed from the skeleton; unfortunately, measurements with the skeleton provided unreliable excitation spectra and therefore the coral tissue needed to be removed for measurements.

It is interesting to note that the excitation peaks of CFP and GFP fall on either side of the chlorophyll absorbance peaks, which may reduce competition for particular wavelengths of PAR and may be evidence of energy partitioning. Having FPs and antennae complexes with distinct maximum absorbance peaks may signal an evolutionary change to avoid competition for irradiance. However, the excitation peak, and in particular that of CFP as well as intact light-harvesting complexes, are broad and therefore there may be some overlap between wavelengths that can be absorbed by FPs or photosynthetic pigments. But, because of the distance between FPs and antenna complexes, energy cannot be directly transferred from coral FPs to Symbiodinium in shallow corals (Gilmore et al. 2003). Nonetheless, it may be possible for antenna complexes to absorb re-emitted wavelengths from FPs. However, the data in this study show that CFP and GFP absorption have limited impact on symbiont photosynthesis in mesophotic corals, and this would be particularly true under the extremely low-irradiance regimes in winter months. This finding is similar to that from shallow Caribbean corals, where a study also concluded that FP absorption, emission, and reflection has an insignificant effect on Symbiodinium photosynthesis (Mazel et al. 2003).

Additional perspective is gained in examining the photosynthetic parameters $\mathrm{rETR}_{\max }, \alpha, E_{\mathrm{k}}$ and $F_{\mathrm{v}} / F_{\mathrm{m}}$ in both fluorescent and nonfluorescent corals. There were no detectable differences between these corals, suggesting that Symbiodinium photophysiology is not influenced by coral fluorescence. Because spectral features influence photosynthetic measurements (Mass et al. 2010), it is possible that using an irradiance source with a spectrum similar to the native habitat of these corals rather than the white light that was available would have produced a different result. For example, in Stylophora pistillata from $40 \mathrm{~m}$, the ratio of gross photosynthesis to respiration doubled when measured under blue light as opposed to full spectrum light (Mass et al. 2010). In the Red Sea, the mesophotic-restricted coral Leptoseris fragilis has an unidentified coral fluorescent pigment that is hypothesized to be involved in improving the photosynthesis of Symbiodinium because higher photosynthetic rates were obtained with a narrow spectrum of light matching the excitation of the fluo- rescent pigment at some light intensities (Schlichter \& Fricke 1990). The fluorescent pigment of $L$. fragilis has a peak emission $(\sim 40 \mathrm{~nm})$ that overlaps with the peak absorbance of chl a (Schlichter \& Fricke 1990). It is not possible to measure the emission of a FP in chloroform because FPs degrade in chloroform, and therefore it seems unlikely that the fluorescent pigment in L. fragilis is a FP (Matz et al. 2006a). Unfortunately, the fluorescent pigment for $L$. fragilis was not characterized further and remains unidentified. In contrast, the FPs of Hawaiian mesophotic Leptoseris did not have any influence over the photophysiology of Symbiodinium in mesophotic corals, with the methods used here.

This study provides a first characterization of the prevalence and types of coral FPs and fluorescence emission phenotypes in dominant mesophotic reefbuilding corals and suggests that FPs are important for coral physiology. Because of the difficulty of obtaining samples from the mesophotic zone, this study does have limitations of modest sample sizes, particularly when trying to compare among different depths and species. However, this study offers a foundation for coral fluorescence in the mesophotic zone and hopefully will stimulate more research in this direction. Future research could investigate the relationship between FP gene expression, FP abundance within coral tissues, and localization of FPs over depth. Microscopy measurements on the spatial separation between FPs and Symbiodinium will confirm or refute the possibility of energy transfer. While the focus of this study was broad in including 4 closely related species over a large depth range (65-125 m), future studies targeting a specific Leptoseris species, perhaps with only 2 depth ranges (e.g. a shallow versus deeper site) and including reciprocal transplant experiments and additional physiological measurements, such as oxygen evolution, under a variety of irradiance intensities and spectral qualities, may improve the understanding of the role of FPs in corals. While this study was focused on the ecological characterization among dominant corals of the mesophotic zone and does not determine the function of FPs in mesophotic corals, this study can provide evidence to support or negate various hypotheses.

\section{On the function of FPs}

Despite early observations of coral fluorescence and the widespread use of FPs as a tool in research, the function of FPs in shallow and deep corals 
remains unknown. The inability to conduct laboratory work to knockdown/knockout genes in corals or in situ manipulations at depth does not allow for conclusive studies on the function of FPs. Moreover, recent studies have showed conflicting results, leading to multiple hypotheses on the functions of FPs. FPs from distinct corals from disparate environments are likely to have unique functions. The present study on coral fluorescence of dominant mesophotic reef-building corals has implications for the prevailing hypotheses of FPs.

In irradiance-limiting environments, it is hypothesized that coral FPs could enhance photosynthesis of their endosymbiotic algae by converting nonharvested PAR wavelengths into wavelengths of irradiance that can be absorbed by the light-harvesting pigment protein complexes of Symbiodinium (Salih et al. 2000). The position of FPs within the host tissue can vary; low-light corals have FPs localized below or within Symbiodinium populations, whereas in highlight corals, FPs are located above Symbiodinium (Salih et al. 2000). However, fluorescence kinetics and mapping of excitation and emission in shallow corals show that FP emission can only play a minor role in chlorophyll excitation (Gilmore et al. 2003). Additionally, measurements on reflectance and chlorophyll excitation spectra indicate that FPs have negligible impact on coral photosynthesis under high-irradiance regimes (Mazel et al. 2003). In the present study, the similarity in photosynthetic pigment excitation of the Symbiodinium fraction from corals with CFP, GFP, and no fluorescence emission suggests that it appears unlikely that FPs and photosynthesis are linked. Additionally, the lack of relationship between the abundances and relative abundances of different photosynthetic pigments and coral fluorescence also does not support a role of FP in enhancing photosynthesis in mesophotic corals. Furthermore, the photosynthetic parameters were similar between corals with and without fluorescence, suggesting little or no relationship between FPs and the symbiont photosynthesis. Ultimately, the lack of increase in proportion of corals with fluorescence at greater depths, combined with the data on the concentrations of photosynthetic pigments, photosynthetic pigment excitation, and photosynthetic parameters, suggest that these mesophotic FPs are not involved in augmenting photosynthesis of Symbiodinium, but rather may serve another function in mesophotic corals.

Another leading hypothesis for the function of FPs in shallow corals is for photoprotection (Salih et al. 2000, D'Angelo et al. 2008, Roth et al. 2010). Photo- protection, the processes and mechanisms to prevent damage from light, is important for both the coral as well as Symbiodinium. Photoprotection by FPs could include absorbing, screening, and scattering light as well as acting as an antioxidant (Salih et al. 2000, Gilmore et al. 2003, Bou-Abdallah et al. 2006, Palmer et al. 2009a). Ultraviolet radiation, PAR, and to a lesser extent blue light ( 410-480 nm) are greatly reduced at mesophotic depths (Kirk 1994, Kahng et al. 2012, the present study). Mesophotic corals independent of their photosymbionts also express FPs. Carijoa riisei, an ahermatypic coral found from 0 to $125 \mathrm{~m}$, has green-colored FPs on the anthocodia (distal part of a polyp) at all depths, which are hypothesized to serve a photoprotective role (Kahng \& Salih 2005). In the present study, CFP absorbed the highest-energy wavelengths of light that would reach Leptoseris spp. and show a decline in abundance in corals with depth, which may suggest that CFPs could serve a photoprotective function, particularly for corals at $<100 \mathrm{~m}$ depth. However, this selection pressure may only be present during the summer months, as winter may reduce irradiance from both lower intensities and shorter days. Shallow corals can use FPs to photoacclimate to different light intensities and spectral distributions (D'Angelo et al. 2008, Roth et al. 2010). The photosynthetic apparatus of Symbiodinium acclimates to both light intensity and spectral features of PAR (see Roth 2014), which could be influenced by FPs in corals. It has also been hypothesized that FPs could help regulate Symbiodinium through photosynthesis modulation and through regulatory photosensors (Field et al. 2006), but no differences in photosynthesis and photosynthetic pigments in fluorescent and nonfluorescent corals were observed in the present study.

While irradiance is much reduced at mesophotic depths, it is unclear if photosynthetic organisms in the mesophotic zone experience any excessive light. In reef-building shallow corals, multiple scattering by the coral skeleton increases the amount of light the coral cells and Symbiodinium are exposed to and offers many opportunities for photons of light to be absorbed or damage cells (Kühl et al. 1995, Enríquez et al. 2005). It has been hypothesized that the skeleton of mesophotic Leptoseris spp. may be specialized to increase the local light field within coral cells (Kahng et al. 2012), but detailed studies on the scatter and skeletal fractality of mesophotic Leptoseris spp. are lacking. Mesophotic corals also often have flattened skeleton morphologies to optimize light absorption (Kühlmann 1983). In shallow corals, blue light increases susceptibility to bleaching during thermal 
stress and bleaching of cultured Symbiodinium (Fitt \& Warner 1995), perhaps because blue light is known to damage photosystem II and inhibit its repair (Nishiyama et al. 2006). While the irradiance in the mesophotic zone is quite low, at noon in summer months, the PAR was measured to be higher than the photosynthetic saturating irradiance $\left(E_{\mathrm{k}}\right)$ of these corals. Once the saturation irradiance is exceeded, additional irradiance cannot be processed through photochemistry and the surplus light energy must be dissipated via other pathways such as nonphotochemical quenching to prevent excessive production of reactive oxygen species and ultimately damage (see Roth 2014). Non-photochemical quenching, the dissipation of extra energy as heat, encompasses multiple processes on many timescales (see Roth 2014). Both hot and cold temperature anomalies increase the need for photoprotection under typical irradiances (Roth et al. 2012, Roth 2014). Mesophotic corals experience rapid reductions in temperatures from internal waves and upwelling (Bak et al. 2005, Lesser et al. 2009) and photoprotection may be necessary during those conditions. The extent to which mesophotic corals experience excess light and need and/or utilize these mechanisms is unknown.

FPs may also be able to act as antioxidants, which scavenge and neutralize reactive oxygen species (Mazel et al. 2003, Bou-Abdallah et al. 2006, Palmer et al. 2009a). Reactive oxygen species can damage proteins, lipids, and DNA (Lesser 2006). The production and accumulation of reactive oxygen species can be very dangerous for organisms and is termed oxidative stress (Lesser 2006). Reactive oxygen species are a common response to a variety of environmental insults such as temperature stress, light stress, and pollution (Lesser 2006). Additionally, the production of reactive oxygen species is inevitable during photosynthesis regardless of irradiance intensity (Foyer \& Shigeoka 2011). Corals host Symbiodinium that are photosynthesizing and producing oxygen and reactive oxygen species within the cells of corals; therefore, shallow corals become hyperoxic during the daytime and are highly susceptible to oxidative stress (Kühl et al. 1995, Lesser 2006, Roth 2014). Mesophotic reefbuilding corals also host Symbiodinium, but it is unknown how vulnerable mesophotic coral-Symbiodinium symbioses are to oxidative stress at depth and how often the symbioses would encounter conditions to elicit oxidative stress. In this study, mesophotic Symbiodinium have similar concentrations of photoprotective pigments per cell, xanthophylls and $\beta$ carotene, as compared to Symbiodinium from shallow corals (Apprill et al. 2007). Because xanthophylls help dissipate excess energy as heat and xanthophylls and $\beta$-carotene serve as antioxidants (Lesser 2006), the equal presence of photosynthetic protective pigments in mesophotic and shallow corals may suggest a need to have defenses to neutralize reactive oxygen species even at depth. The high abundance of FPs throughout the mesophotic zone and in particular at the deepest range (120-125 m) may indicate that these proteins play an integral and conserved role in coral biology such as in scavenging reactive oxygen species.

Other roles proposed for the function of FPs include their visual properties. FPs are responsible for the vivid coloration of shallow corals (Dove et al. 2001). Because of the blue spectral enrichment at mesophotic depths, the cyan/green fluorescence is easily visible for the human eye at depth from the submersible. The coral fluorescence may be part of a countershading or camouflage from herbivorous fishes, which has been suggested for shallow corals (Matz et al. 2006b). Although mesophotic reefs can support significant fish biomass, they are dominated by planktivores (Kahng et al. 2014). Given the high abundance of corals and low abundance of herbivores, it seems unlikely that Leptoseris spp. would need camouflage as protection from fish in these ecosystems. Additionally, it has been hypothesized that coral fluorescence could be used to attract Symbiodinium (Hollingsworth et al. 2004). However, the present study showed similar densities of Symbiodinium regardless of fluorescence, suggesting that this is not a likely function of FPs in mesophotic corals. It also seems probable that free-living Symbiodinium would not be able to survive in the low-irradiance mesophotic habitat and that Symbiodinium within mesophotic corals may require products from the host to survive in such light-limiting conditions. It may be possible that coral fluorescence could attract prey, which could be beneficial to increase heterotrophy at depth, but this hypothesis has been largely untested.

Lastly, FPs may have a role in coral immunity (Palmer et al. 2009b, D'Angelo et al. 2012). It is common to observe varied fluorescence and in particular RFP near a coral parasite, borer, an erosion area, or other disturbance (Palmer et al. 2009b, D'Angelo et al. 2012). However, it is unlikely that the coral fluorescence observed in this study is from a diseaserelated scenario because the fluorescence phenotype patterns match with anatomical regions rather than a disturbance or variation in the tissue. However, we cannot exclude the possibility that mesophotic corals could express different FPs during wounds and healing because this was not tested in this study. In shal- 
low corals, FPs are known to correlate with growth in addition to wound healing (Roth et al. 2010, D'Angelo et al. 2012, Roth \& Deheyn 2013), which may suggest another basic physiological role. It is remarkable that FPs are pervasive and fluorescence is primarily cyan/green on mesophotic coral reefs, which is similar to shallow coral reefs.

\section{CONCLUSION}

This study encompassed the ecology of coral FPs in an extreme low-irradiance environment and considerable Symbiodinium physiological data to provide new insights into MCEs and coral fluorescence with implications on the function of FPs. While it appears unlikely that FPs in mesophotic Leptoseris spp. corals enhance photosynthesis, based on this study we cannot rule out the possibility that mesophotic FPs could play a photoprotective type role either through absorption, screening, or scattering of light or as an antioxidant. Many of these corals are exposed to light levels higher than their photosynthetic saturating irradiance and the broad excitation peaks of FPs have some overlap in wavelengths of light used in photosynthesis, which could provide some dissipation of light to wavelengths of light less used by photosynthesis. There is the potential for energy partitioning, as the main excitation peaks of the FPs fall on either side of the main photosynthetic peak, which may reduce competition and be important in an energy-limited environment. Additionally, we cannot rule out that fluorescence could be a remnant from a function no longer relevant for mesophotic corals. However, because mesophotic corals reduce their energetic requirements associated with the difficulties of living and thriving in such low-light environments (Lesser et al. 2009, Kahng et al. 2010), the widespread prevalence of coral fluorescence in 4 dominant reef-building corals throughout the mesophotic zone is unexpected. Furthermore, it is surprising that these corals appear to dedicate a significant amount of energy towards producing FPs, which are often present over the entire coral (coenosarc and oral disc), and suggests that the FPs have a significant role in coral and/or symbiont biology.

Acknowledgements. We thank the Hawai'i Undersea Research Laboratory (HURL) 'Pisces V' submersible and 'RCV-150' pilots, crew, and support staff, as well as the crew of the R/V 'Ka imikai-o-Kanaloa', for access to these amazing depths. Funding for coral collections was provided by the NOAA Coastal Ocean Program, under award NA07NOS4780187 to the University of Hawai'i (awarded to C.M.S. and H.L.S.), and submersible support by NOAA Undersea Research Program's Hawai'i Undersea Research Laboratory under award NA05OAR4301108 (awarded to C.M.S. and H.L.S.). Genetic and physiological analyses were funded by grants from the National Science Foundation (NSF) Experimental Program to Stimulate Competitive Research (EPSCoR) (EPS-0903833), and Bio Oce (OCE0752604 awarded to R.D.G.). Work by M.S.R. was supported by the Division of Chemical Sciences, Geosciences, and Biosciences, Office of Basic Energy Sciences, Office of Science, U.S. Department of Energy, FWP number 449B and the Agriculture and Food Research Initiative Competitive Grant No. 2013-67012-21272 from the USDA National Institute of Food and Agriculture. Funding from the New Zealand Ministry of Business, Innovation and Employment (contract CAWX1208) supported X.P. during manuscript preparation. Coral samples were collected under SAP permit 2009-72 from the Board of Land and Natural Resources, State of Hawai'i. However, the majority of corals were collected in US Federal Waters, and did not require a permit for collection. We thank F. Parrish for use of fluorescence NightSea equipment; B. Popp, A. Grottoli, J. Rooney and K. Binsted for assistance collecting and processing samples during the cruise; F. Butler and K. Selph for assistance in processing samples after the cruise; and Z. Forsman and D. Luck for assistance with coral genetic interpretation. This is the School of Ocean and Earth Science and Technology contribution 9262 and Hawaii Institute of Marine Biology Contribution 1612 .

\section{LITERATURE CITED}

Alieva NO, Konzen KA, Field SF, Meleshkevitch EA and others (2008) Diversity and evolution of coral fluorescent proteins. PLoS ONE 3:e2680

Apprill A, Bidigare RR, Gates RD (2007) Visibly healthy corals exhibit variable pigment concentrations and symbiont phenotypes. Coral Reefs 26:387-397

Bak RP, Nieuwland G, Meesters EH (2005) Coral reef crisis in deep and shallow reefs: 30 years of constancy and change in reefs of Curacao and Bonaire. Coral Reefs 24: 475-479

Bidigare R, Van Heukelem L, Trees C (2005) Analysis of algal pigments by high-performance liquid chromatography. In: Andersen R (ed) Algal culturing techniques. Academic Press, New York, NY, p 327-345

Bou-Abdallah F, Chasteen ND, Lesser MP (2006) Quenching of superoxide radicals by green fluorescent protein. Biochim Biophys Acta 1760:1690-1695

Bricaud A, Claustre H, Ras J, Oubelkheir K (2004) Natural variability of phytoplanktonic absorption in oceanic waters: influence of the size structure of algal populations. J Geophys Res 109:C11010, doi:10.1029/2004JC 002419

> D'Angelo C, Denzel A, Vogt A, Matz MV and others (2008) Blue light regulation of host pigment in reef-building corals. Mar Ecol Prog Ser 364:97-106

$>$ D'Angelo CD, Smith EG, Oswald F, Burt J, Tchernov D, Wiedenmann J (2012) Locally accelerated growth is part of the innate immune response and repair mechanisms in reef-building corals as detected by green fluorescent 
protein (GFP)-like pigments. Coral Reefs 31:1045-1056

Dove SG, Hoegh-Guldberg O, Ranganathan S (2001) Major colour patterns of reef-building corals are due to a family of GFP-like proteins. Coral Reefs 19:197-204

Enríquez S, Méndez ER, Iglesias-Prieto R (2005) Multiple scattering on coral skeletons enhances light absorption by symbiotic algae. Limnol Oceanogr 50:1025-1032

Falkowski PG, Jokiel PL, Kinzie RA (1990) Irradiance and corals. In: Dubinsky Z (ed) Ecosystems of the world: coral reefs, Vol 25. Elsevier, Amsterdam, p 89-107

- Field SF, Bulina MY, Kelmanson IV, Bielawski JP, Matz MV (2006) Adaptive evolution of multicolored fluorescent proteins in reef-building corals. J Mol Evol 62:332-339

Fitt WK, Warner ME (1995) Bleaching patterns of four species of Caribbean reef corals. Biol Bull (Woods Hole) 189: 298-307

Foyer CH, Shigeoka S (2011) Understanding oxidative stress and antioxidant functions to enhance photosynthesis. Plant Physiol 155:93-100

Frenette J, Demers S, Legendre L, Dodson JJ (1993) Lack of agreement among models for estimating photosynthetic parameters. Limnol Oceanogr 38:679-687

Gilmore AM, Larkum AWD, Sallh A, Itoh S and others (2003) Simultaneous time resolution of the emission spectra of fluorescent proteins and zooxanthellar chlorophyll in reef-building coral. Photochem Photobiol 77:515-523

> Gruber DF, Kao HT, Janoschka S, Tsai J, Pieribone VA (2008) Patterns of fluorescent protein expression in scleractinian corals. Biol Bull (Woods Hole) 215:143-154

Hollingsworth L, Krupp D, Lewis T, Leong J (2004) Early onset and expression of green fluorescent proteins (GFPs) in the larvae of the mushroom coral, Fungia scutaria Lamarck 1801. In: Proc 10th Int Coral Reef Symp, Okinawa, p 99-105

Kahng SE, Salih A (2005) Localization of fluorescent pigments in a nonbioluminescent, azooxanthellate octocoral suggests a photoprotective function. Coral Reefs 24:435

Kahng SE, Garcia-Sais JR, Spalding HL, Brokovich E and others (2010) Community ecology of mesophotic coral reef ecosystems. Coral Reefs 29:255-275

> Kahng SE, Hochberg EJ, Apprill A, Wagner D, Luck DG, Perez D, Bidigare RR (2012) Efficient light harvesting in deep-water zooxanthellate corals. Mar Ecol Prog Ser 455:65-77

Kahng SE, Copus JM, Wagner D (2014) Recent advances in the ecology of mesophotic coral ecosystems (MCEs). Curr Opin Environ Sustain 7:72-81

Kao HT, Sturgis S, DeSalle R, Tsai J, Davis D, Gruber D, Pieribone V (2007) Dynamic regulation of fluorescent proteins from a single species of coral. Mar Biotechnol 9: 733-746

Kirk JTO (1994) Light and photosynthesis in aquatic ecosystems. Cambridge University Press, New York, NY

Kühl M, Cohen Y, Dalsgaard T, Jorgensen BB, Revsbech NP (1995) Microenvironment and photosynthesis of zooxanthellae in scleractinian corals studied with microsensors for $\mathrm{O}_{2}$, pH and light. Mar Ecol Prog Ser 117:159-172

Kühlmann DHH (1983) Composition and ecology of deepwater coral associations. Helgol Meeresunters 36: 183-204

Lesser MP (2006) Oxidative stress in marine environments: biochemistry and physiological ecology. Annu Rev Physiol 68:253-278

Lesser MP, Slattery M, Leichter JJ (2009) Ecology of mesophotic coral reefs. J Exp Mar Biol Ecol 375:1-8

Leutenegger A, D'Angelo C, Matz MV, Denzel A and others (2007) It's cheap to be colorful. Anthozoans show a slow turnover of GFP-like proteins. FEBS J 274:2496-2505

Luck DG, Forsman ZH, Toonen RJ, Leicht SJ, Kahng SE (2013) Polyphyly and hidden species among Hawai'i's dominant mesophotic coral genera, Leptoseris and Pavona (Scleractinia: Agariciidae). PeerJ 1:e132

Maragos JE, Jokiel PL (1986) Reef corals of Johnston Atoll: one of the world's most isolated reefs. Coral Reefs 4: 141-150

Marsh JA Jr (1970) Primary productivity of reef-building calcareous red algae. Ecology 51:255-263

- Mass T, Kline DI, Roopin M, Veal CJ, Cohen S, Iluz D, Levy O (2010) The spectral quality of light is a key driver of photosynthesis and photoadaptation in Stylophora pistillata colonies from different depths in the Red Sea. J Exp Biol 213:4084-4091

Matz MV, Labas YA, Ugalde J (2006a) Evolution of function and color in GFP-like proteins. In: Chalfie M, Kain SR (eds) Green fluorescent protein: properties, applications, and protocols, 2nd edn. John Wiley \& Sons, Hoboken, NJ, p 139-161

Matz MV, Marshall NJ, Vorobyev M (2006b) Symposium-inprint: green fluorescent protein and homologs. Photochem Photobiol 82:345-350

> Mazel CH, Lesser MP, Gorbunov MY, Barry TM, Farrell JH, Wyman KD, Falkowski PG (2003) Green-fluorescent proteins in Caribbean corals. Limnol Oceanogr 48:402-411

Muscatine L (1990) The role of symbiotic algae in carbon and energy flux in reef corals. In: Dubinsky Z (ed) Ecosystems of the world, Vol 25. Elsevier, Amsterdam, p 75-87

> Nishiyama Y, Allakhverdiev SI, Murata N (2006) A new paradigm for the action of reactive oxygen species in the photoinhibition of photosystem II. Biochim Biophys Acta 1757:742-749

> Padilla-Gamiño JL, Bridigare RR, Barshis DJ, Alamaru A and others (2013) Are all eggs created equal? A case study from the Hawaiian reef-building coral Montipora capitata. Coral Reefs 32:137-152

Palmer CV, Modi CK, Mydlarz LD (2009a) Coral fluorescent proteins as antioxidants. PLoS ONE 4:e7298

Palmer CV, Roth MS, Gates RD (2009b) Red fluorescent protein responsible for pigmentation in trematode-infected Porites compressa tissues. Biol Bull (Woods Hole) 216: $68-74$

Pochon X, Putnam H, Burki F, Gates R (2012) Identifying and characterizing alternative molecular markers for the symbiotic and free-living dinoflagellate genus Symbiodinium. PLoS ONE 7:e29816

> Pochon X, Forsman ZH, Spalding HL, Padilla-Gamiño JL, Smith CM, Gates RD (2015) Depth specialization in mesophotic corals (Leptoseris spp.) and associated algal symbionts in Hawai'i. R Soc Open Sci 2:140351

> Pooyaei Mehr SF, DeSalle R, Kao HT, Narechania A and others (2013) Transcriptome deep-sequencing and clustering of expressed isoforms from Favia corals. BMC Genomics 14:546

- Ralph P, Gademann R (2005) Rapid light curves: a powerful tool to assess photosynthetic activity. Aquat Bot 82: 222-237

Rooney J, Donham E, Montgomery A, Spalding H and others (2010) Mesophotic coral ecosystems in the Hawaiian 
Archipelago. Coral Reefs 29:361-367

Roth MS (2014) The engine of the reef: photobiology of the coral-algal symbiosis. Front Microbiol 5:422

Roth MS, Deheyn DD (2013) Effects of cold stress and heat stress on coral fluorescence in reef-building corals. Sci Rep 3:1421

Roth MS, Latz MI, Goericke R, Deheyn DD (2010) Green fluorescent protein regulation in the coral Acropora yongei during photoacclimation. J Exp Biol 213:3644-3655

Roth MS, Goericke R, Deheyn DD (2012) Cold induces acute stress but heat is ultimately more deleterious for the reefbuilding coral Acropora yongei. Sci Rep 2:240

Roth MS, Fan TY, Deheyn DD (2013) Life history changes in coral fluorescence and the effects of light intensity on larval physiology and settlement in Seriatopora hystrix.

Editorial responsibility: Charles Birkeland,

Honolulu, Hawaii, USA
PLoS ONE 8:e59476

Salih A, Larkum A, Cox G, Kühl M, Hoegh-Guldberg O (2000) Fluorescent pigments in corals are photoprotective. Nature 408:850-853

Schlichter D, Fricke HW (1990) Coral host improves photosynthesis of endosymbiotic algae. Naturwissenschaften 77:447-450

Smith EG, D'Angelo C, Salih A, Wiedenmann J (2013) Screening by coral green fluorescent protein (GFP)-like chromoproteins supports a role in photoprotection of zooxanthellae. Coral Reefs 32:463-474

Vermeij MJA, Delvoye L, Nieuwland G, Bak RPM (2002) Patterns in fluorescence over a Caribbean reef slope: the coral genus Madracis. Photosynthetica 40:423-429

Submitted: May 26, 2014; Accepted: October 31, 2014

Proofs received from author(s): January 28, 2015 